\title{
PENGARUH SERVICESCAPE TERHADAP BEHAVIORAL INTENTION \\ DI KAFE KUPU-KUPU \\ (Survei Terhadap Tamu Yang Melakukan Pembelian di Kafe Kupu-Kupu)
}

\author{
Friga Statifiansyah \\ Gitasiswhara
}

\begin{abstract}
Abstrak
This aims to find the influence of service scape to the behavioral intention for visitors at the restaurant. Many researchers have already discovered that people dine in the restaurant, not just because of the food taste, but also the ambience or physical attributes. Many restaurants have attempted to design its service scape to create a competitive advantage for surpassing the competitors. The variables studied in this research are service scape, as the independent variable, and the behavioral intention as the dependent one. The dimension of service scape consists of the ambient conditions, spatial layout, sign and symbols. Whereas, the dimension of behavioral intention consists of repurchase intention and the tendency of spreading the word-of-mouth about the restaurant. The instrument of this research was questionnaires that are distributed to 100 respondents. The multiple regression's statistical tool was used for analyzing the data and assisted by SPSS 18. The result indicated that the sign and symbol had the highest impact to the behavioral intention.
\end{abstract}

Keywords: Servicescape, Behavioral Intention.

\section{PENDAHULUAN}

Kafe Kupu-Kupu merupakan sebuah perusahaan yang didirikan pada bulan April 2009 setelah sebelumnya beberapa pendirinya menjalankan usaha di bidang lain. Melihat peluang belum adanya rumah makan yang berbentuk kafe di Kolonel Masturi, Bandung Barat maka para pendiri sepakat untuk mendirikan sebuah kafe dengan nama Kafe Kupu-Kupu setelah sebelumnya mendirikan sebuah CV bernama CV Ranah Hidup Sejahtera yang membawahi kafe tersebut secara hukum.

Merupakan sebuah restoran dining yang bersifat kafe, tentunya memiliki keunikan dari tema yang mereka ambil, yaitu kupu-kupu. Selain itu untuk memberikan kesan yang edukatif, Kafe Kupu-Kupu mengusung konsep book and art yaitu dengan menyediakan fasilitas buku bacaan yang ditata rapi di rak untuk para tamu yang berkunjung, sebari menyantap makanan dan minuman, tamu pun dapat membaca buku yang telah disediakan. Menawarkan atmosphere yang baik karena terletak di daerah yang tinggi, sehingga selain dari segi makanan dan minuman, tamu pun dapat melihat kota Cimahi dan sekitarnya dari tempat makan.

Sebagai usaha yang bergerak di bidang penyedia jasa makanan dan minuman khususnya restoran yang utamanya menyediakan makanan dan minuman, Kafe Kupu-Kupu juga menyediakan beberapa produk dan pelayanan lain diantaranya:

1. Dining Menu

Diperuntukan bagi tamu regular yang datang ke Kafe Kupu-Kupu, tamu dapat memilih menu makanan mulai dari cemilan (dari 7rb $16 \mathrm{rb}$ ), makanan Indonesia (dari 12rb-30rb), western (dari 15rb-50rb) dan varian minuman mulai dari softdrink, kopi, the dan masih banyak yang lainnya (dari 3rb-20rb).

2. Meeting Package

Kafe Kupu-Kupu menyediakan paket untuk meeting di lantai 2, dengan luas ruangan $20 \mathrm{mx} 10 \mathrm{~m}$ dapat diset sedemikian rupa untuk keperluan meeting tamu.Dengan harga yang ditawarkan sebesar Rp35.000, tamu sudah dapat coffee break dan lunch.

3. WeddingPackage

Wedding package yang disediakan Kafe Kupu-Kupu sudah termasuk hidangan buffet untuk tamu undangan, dekorasi, kue pengantin, stall makanan tambahan, live music, dan fasilitas pendukung lainnya.

4. Kids Birthday

Acara ulang tahun anak dapat dilaksanakan di Kafe Kupu-Kupu dengan dekor sedemikian rupa yang bertemakan ulang tahun dan makanan yang disesuaikan untuk anak-anak.

Kafe Kupu-Kupu pun menyediakan kue ulang tahun khusus untuk si anak.

Kafe Kupu-Kupu sebagai tempat makan yang mengusung konsep Book and Art yang mementingkan kenyamanan pengunjung selama berada di Kafe Kupu-Kupu, sehingga pengunjung diharapkan melakukan pembelian ulang jika kesan pertama tamu baik dan betah berlama-lama berada di Kafe Kupu-Kupu untuk menikmati makanan yang disediakan Kafe Kupu-Kupu. Dari hal tersebut penulis ingin mengetahui sampai sejauh 
mana perilaku tamu yang berkunjung ke Kafe Kupu-Kupu, maka dilakukan Pra penelitian mengenai behavioral intention yang ditujukan kepada 30 orang tamu yang pernah berkunjung ke Kafe Kupu-Kupu. Dalam pra penelitian ini digunakan tiga atribut behavioral intention yaitu repurchase intention (melakukan pembelian ulang), price premium (membayar lebih) dan word of mouth (merekomendasikan pada orang lain). Adapun hasilnya dapat dapat dilihat pada gambar dibawah ini :

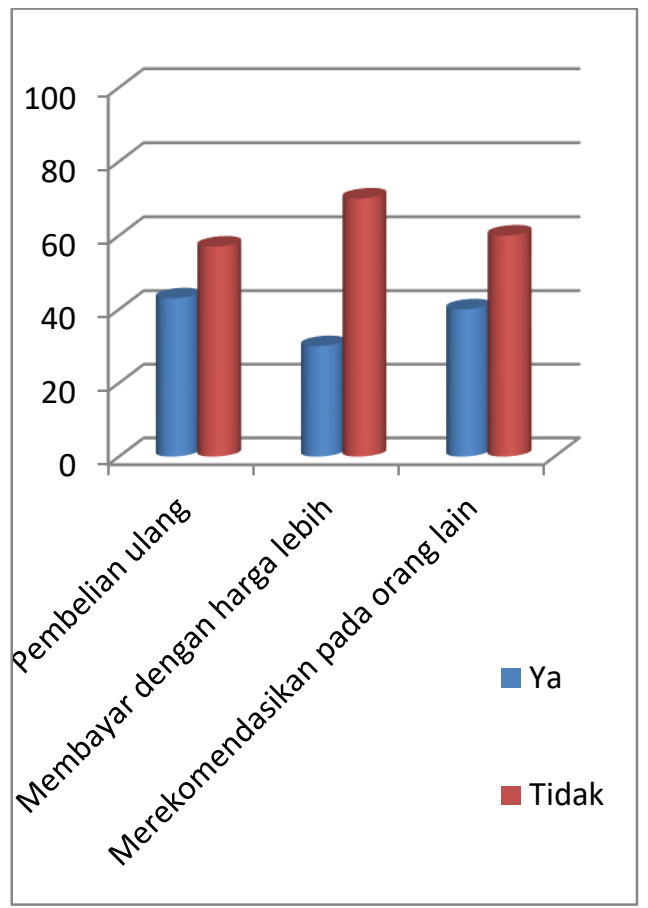

Gambar 1

Hasil Pra Penelitian

Berdasarkan Gambar 1 dapat diketahui bahwa hanya sebanyak $43 \%$ yang akan melakukan pembelian ulang ke Kafe Kupu-Kupu, lalu untuk membayar lebih dengan fasilitas atau jasa yang diberikan Kafe Kupu-Kupu hanya 30\% yang ingin membayar lebih dan hanya $40 \%$ saja yang bersedia untuk merekomedasikan Kafe KupuKupu ke orang lain. Dari presentase tersebut dapat dilihat bahwa terdapat masalah apabila tamu yang datang tidak ingin berkunjung kembali, dan akan berdampak pada berkurangnya kunjungan ke Kafe Kupu-Kupu setiap tahunnya, seperti yang dapat kita lihat dari tabel disamping:

Tabel 1

Jumlah Kunjungan Wisatawan ke Kafe Kupukupu tahun 2012-2014

\begin{tabular}{|c|c|c|}
\hline Tahun & $\begin{array}{c}\text { Jumlah } \\
\text { Kunjungan }\end{array}$ & $\begin{array}{c}\text { Tingkat } \\
\text { Pertumbuhan }\end{array}$ \\
\hline 2012 & 23.907 & - \\
\hline 2013 & 23.578 & Turun $1.38 \%$ \\
\hline 2014 & 23.397 & Turun $0,77 \%$ \\
\hline
\end{tabular}

Sumber : Manajemen Kafe Kupu-Kupu 2015

Melihat dari tabel 1 behavioral intention dan data kunjungan di Kafe Kupu-Kupu tidak begitu bagus maka behavioral intention dan kunjungan perlu ditingkatkan dengan strategi yang dimiliki Kafe Kupu-Kupu baik dari segi pemasaran atau fasilitas-fasilitas penunjang. Fasilitas penunjang seperti design interior ataupun eksterior dan mengemasnya secantik mungkin agar tamu tertarik.

Mengemas suatu produk menjadi salah satu strategi yang dilakukan restoran atau kafe untuk menarik kunjungan, memberikan nilai lebih dan merangsang konsemen untuk datang. Di dalamnya terdapat fasilitas fisik (servicescape) seperti penataan cahaya, atmosphere, bangunan dan brand/sign. Penilaian bagus atau tidaknya sebuah restoran tidak berkutat hanya pada kualitas ataupun kuantitas makanan saja. Menurut Fitzsimmons (2011:154) servicescape adalah fasilitas fisik dalam pelayanan yang didesain untuk kebutuhan tamu untuk mempengaruhi perilaku tamu dan memuaskan tamu dimana desain fasilitas fisik akan memberikan dampak yang positif terhadap tamu dan karyawan.

Yang artinya adalah servicescape adalah sebagai salah satu alat pemuas kebutuhan konsumen selain makanan dan minuman yang disedikan kafe. serangkaian acara yang nyata maupun tidak nyata dari pengalaman pelanggan ketika sedang makan. Faktor - faktor servicescape terbagi menjadi 3 aspek yaitu ambient condition (karakter lingkungan), spatial layout and functionality (penataan) dan sign, symbol, and artifacts (Merek). Melalui strategi servicescape ini diharapkan dapat menjadi penghubung antara kafe dan pengunjungnya untuk menciptakan hubungan yag baik.

Berdasarkan fenomena yang terjadi penulis bermaksud mengadakan penelitian dengan judul "Pengaruh Servicescape Terhadap Behavioral Intention di Kafe Kupu-Kupu (Survei Terhadap Tamu yang Melakukan Pembelian di Kafe Kupu-Kupu).

\section{KAJIAN PUSTAKA}

Pemasaran merupakan salah satu dari kegiatan-kegiatan pokok yang dilakukan oleh para pengusaha dalam usahanya untuk mempertahankan kelangsungan hidupnya, untuk berkembang dan mendapatkan laba. Berhasil tidaknya dalam bpencapaian tujuan bisnis tergantung pada keahlian mereka di bidang pemasaran, produksi, keuangan, maupun dibidang lain. Selain itu juga tergantung pada kemampuan mereka untuk mengkombinasikan fungsi-fungsi tersebut agar organisasi dapat berjalan lancar. 
Pemasaran menurut Kotler dan Amstrong (2014:27) yaitu "marketing as the process by which companies create value for customers and build strong customer relationships in order to capture value from customers in return", artinya adalah proses dimana perusahaan menciptakan nilai bagi pelanggan dan membangun hubungan yang kuat dengan pelanggan, dengan tujuan menangkap nilai dari pelanggan sebagai imbalannya.

Dalam penelitian ini lebih diperkecil skala pemasaran bagi industri pariwisata, menurut Prof. Dr. Salah Wahab, L.J. Crampon, MA dan L.M. Rothfield dalam R.G Soekadijo (2002:218) pemasaran pariwisata adalah suatu proses manajemen yang dilakukan oleh organisasi pariwisata nasional atau perusahaan-perusahaan termasuk dalam kelompok industri pariwisata untuk melakukan identifikasi terhadap wisatawan yang sudah punya keinginan untuk melakukan perjalanan wisata dan wisatawan yang punya potensi untuk melakukan perjalanan wisata dengan jalan melakukan melakukan komunikasi dengan mereka, mempengaruhi keinginan,kebutuhan, memotivasinya terhadap apa yang disukai dan yang tidak disukainya, pada tingkat daerah-daerah lokal,regional, nasional ataupun internasional dengan menyediakan obyek dan atraksi wisata agar wisatawan memperoleh kepuasan optimal.

Sedangkan menurut (Yoety 1990:30) dalam bukunya Tourism Marketing, pemasaran pariwisata adalah suatu system dan koordinasi yang dilaksanakan sebagai suatu kebijakan bagi perusahaan-perusahaan yang bergerak di bidang kepariwisataan, baik milik swasta maupun pemerintah, dalam ruang lingkup lingkup local, regional, nasional dan internasional untuk mencapai kepuasan wisatawan dengan memperoleh keuntungan yang wajar.

Berdasarkan definisi tersebut di atas dapat disimpulkan bahwa pemasaran pariwisata merupakan suatu aktivitas perusahaan atau instansi memberikan informasi yang baik untuk calon konsumen baik skala kecil ataupun besar, agar mereka tertarik dengan kelebihan yang perusahaan miliki dan untuk memenuhi kebutuhan dan keinginan melelui proses pertukaran dimana dalam pemasaran ini kegiatan bisnis dirancang untuk mendistribusikan barang-barang kepada konsumen untuk mencapai sasaranserta tujuan organisasi.

Untuk melakukan kegiatan pemasaran, perusahaan dapat membidik beberapa strategi yang terkandung dalam bauran pemasaran, seperti yang dikatakan Lovelock (2011:44) menyatakan bahwa untuk bauran pemasaran jasa perlu menambahkan 3Ps yaitu: process, physical environment, dan people, secara rinci penjelasan unsur 4Ps dan 3Ps menurut Lovelock (2011:44) sebagai berikut :

1. Product elements, mencakup produk inti yang merespon kebutuhan pelanggan primer dan menyiapkan dari elemen layanan tambahan yang saling memperkuat nilai tambah perangkat yang membantu pelanggan untuk menggunakan produk inti lebih efektif

2. Place and time, mengacu pengiriman elemen produk kepada pelanggan, banyak informasi - elemen yang disampaikan secara elektronik

3. Pricing, termasuk biaya non moneter kepada konsumen dan pertimbangan pengelolaan pendapatan

4. Promotion, juga dipandang sebagai bentuk komunikasi pelanggan dan membimbing pendidikan melalui proses pelayanan, bukan hanya iklan dan promosi.

Pemasaran jasa memerlukan tiga tambahan Ps meliputi manajemen jasa interaksi langsung dengan pelanggan:

1. Process, mengacu pada desain dan pengelolaan proses layanan pelanggan, termasuk permintaan dan mengelola kapasitas dan pelanggan terkait yang menunggu, menerapkan manajemen kualitas layanan yang ketat, pelatihan karyawan yang lebih hati-hati, dan mengotomatisasi tugas yang sebelumnya dilakukan oleh manusia.

2. Physical environment, juga dikenal sebagai servicescape, memberikan bukti nyata dari gambar dan kualitas layanan perusahaan dan memfasilitasi proses pengiriman.

3. People, meliputi perekrutan, pelatihan, dan memotivasi karyawan jasa untuk memberikan kualitas layanan dan produktivitas.

Salah satu strategi yang dapat dipakai perusahaan adalah physical environment stsu yang lebih dikenal dengan servicescape. Menurut Fitzsimmons (2011:154) pengertian servicescape adalah fasilitas fisik dalam pelayanan yang didesain untuk kebutuhan tamu untuk mempengaruhi perilaku tamu dan memuaskan tamu dimana desain fasilitas fisik akan memberikan dampak yang positif terhadap tamu dan karyawan. Sedangkan menurut Lovelock (2011: 4) servicescape merupakan gaya dan tampilan fisik dari elemen pengalaman lain yang ditemui oleh pelanggan di tempat penghantaran jasa.

Berdasarkan definisi dari servicescape diatas dapat disimpulkan servicescape adalah suatu lingkungan dimana konsumen dan penjual berinteraksi, dilengkapi dengan fasilitas dan komunikasi sebagai suatu komoditas yang nyata. Servicescape harus direncanakan agar menarik, 
memuaskan, dan memenuhi segala kegiatan antara konsumen dan penjual secara bersamaan.

Menurut Fitzsimmons (2011:59) dimensi servicescape yang digunakan terdiri dari 3 unsur yaitu ambient conditions, spatial layout and functionality, signs symbols \& artifacts. Dimensi lingkungan fisik yang melatarbelakangi suatu jasa dapat dikategorikan kedalam tiga dimensi komposif sebagai berikut:

\section{a. Ambient Condition}

Merupakan karakteristik lingkungan yang berkenaan dengan kelima panca indera. Latar belakang dari lingkungan seperti suhu, pencahayaan, musik, warna, bau dan gangguan suara). Beberapa ganguan kecil mungkin tidak akan menggangu pelanggan namun jika kondisi lingkungan menjadi ekstrim dapat menjadi masalah serius dan membuat pelanggan tertekan.

\section{b. Spatial Layout and Functionality}

Merupakan denah ruangan, ukuran, dan bentuk dari perlengkapan perabot, meja-meja, mesin dan peralatan yang berpotensi dan cara mereka diatur juga kemampuan benda-benda tersebut untuk memfasilitasi kegiatan transaksi jasa. Pengaturan peralatan dan interior untuk visual dari tampilan fisik dan fungsi-fungsi yang bermanfaat untuk penyerahan atau pelayanan jasa. Tata ruang (spatial layout) mengacu pada bagaimana ruangan tersebut digunakan dan dimana furnitur dan peralatan ditempatkan dalam kamar. Skala dan ukuran properti perhotelan mempengaruhi tata ruang. Fungsionalitas mengacu pada efektivitas tata ruang untuk memfasilitasi pelayanan yang efisien dan memberikan kepuasan pelanggan. Tata ruang harus mencapai keseimbangan optimal antara persyaratan operasional dan harapan pelanggan.

\section{c. Sign, Symbol, and Artifacts}

Tanda-tanda atau simbol juga bentuk bangunan yang mampu mengkomunikasikan tampilan bagi pelanggan. Segala sesuatu yang ada di lingkungan jasa yang berperan sebagai sinyal secara langsung maupun tidak langsung untuk mengkomunikasikan citra perusahaan, membantu pelanggan menemukan arahnya, dan untuk menyampaikan proses pelayanan jasa. Item-item ini bertindak sebagai sinyal eksplisit atau implisit yang mengkomunikasikan tempat pada penggunanya. Tanda petunjuk atau keterangan sebagai sinyal eksplisit, dapat digunakan sebagai label (contoh: nama perusahaan, nama departemen). Sebagai keterangan arah atau tujuan (contoh : masuk, keluar), dan untuk mengkomunikasikan atau berperilaku (contoh : dilarang merokok). Tanda petunjuk dan keterangan yang cukup akan mengurangi persepsi kesimpangsiuran dan stress. Symbol dan artifacts memberikan sinyal komunikasi implicit dan menciptakan daya tarik estetis secara keseluruhan. Sign, symbol, dan artifacts sangat penting sebagai bentuk first impression dari pelanggan dan untuk mengkomunikasikan konsep baru dalam suatu jasa.

Perilaku niat pelanggan terhadap produk dan jasa yang diberikan perusahaan merupakan hasil dari proses kepuasan yang dirasakan pelanggan terhadap produk dan jasa. Kepuasan yang dirasakan pelanggan terhadap produk dan jasa yang telah diberikan dapat memberikan pengaruh perilaku niat pelanggan yang tinggi atau rendah tergantung seberapa besar kepuasan yang dirasakan pelanggan. Pemahaman terhadap perilaku konsumen akan memudahkan perusahaan dalam mengatur dan mengembangkan strategi yang akan dilakukan untuk memenuhi kebutuhan dan keinginan konsumen. Kecenderungan perilaku konsumen adalah seperangkat hasil akhir dari item-item yang termasuk dalam analisa.

Menurut Baker and Crompton (2000:789) mengemukakan bahwa behavioral intention mewakili kemungkinan sikap yang besar terhadap perilaku dan cenderung merefleksikan loyalitas konsumen sebagai predictor yang akurat. Selain itu Hsu (2009:115) juga mengemukakan bahwa behavioral intention mengacu pada upaya tingkat sadar seseorang akan mengerahkan untuk melakukan perilaku dan dapat diukur dengan katadari mulut ke mulut, untuk beralih toko, dan patronase masa depan. Berdasarkan teori tersebut, dapat disimpulkan bahwa behavioral intention adalah suatu indikasi dari bagaimana orang bersedia untuk melakukan perilaku-perilakunya di masa depan dan menanamkan kepercayaan pelanggan terhadap perusahaan sehingga menimbulkan kepuasan tersendiri.

$$
\text { Dalam penelitian ini penulis }
$$
menggunakan dimensi behavioral intention menurut Wahyuningsih (2011:3), yaitu :

1. Repurchase Intention

repurchase intentions yang didefinisikan oleh (Hellier, 2003:1764 dalam Wahyuningsih, 2012:3) sebagai ketetapan keputusan seseorang untuk membeli kembali barang maupun jasa di perusahaan yang sama dalam situasi yang tidak terlampau lama dan dengan lingkungannya.

2. Word of Mouth yang diartikan oleh (Westbrook, 1987:261 dalam Wahyuningsih, 2012:3) sebagai komunikasi informal yang ditujukan kepada konsumen lain tentang perusahaan, pemakaian atau karakteristik produk barang ataupun jasa tertentu.

Ada beberapa premis yang penulis ambil, menurut Fitzsimmons (2011:154): Servicescape adalah 
fasilitas fisik dalam pelayanan yang didesain untuk kebutuhan tamu untuk mempengaruhi perilaku tamu dan memuaskan tamu dimana desain fasilitas fisik akan memberikan dampak yang positif terhadap tamu dan karyawan.

Lalu menurut Lovelock, Wirtz, dan Mussry (2011: 4) mendefinisikan servicescape atau physical environment merupakan gaya dan tampilan fisik dari elemen pengalaman lain yang ditemui oleh pelanggan di tempat penghantaran jasa. Dan yang terakhir menurut Ingrid Y. Lin (2004:176), Servicescape berperan penting dalam berbagai perusahaan jasa seperti hotel dan restoran, servicescape memberikan kesan pertama sebelum konsumen memilih untuk berinteraksi dengan service yang diberikan perusahaan. Servicescape pun berperan penting bagi tamu untuk mempercayai, bersikap dan berharap pada perusahaan. Kemudian konsumen merasakan fasilitas fisik dan menjadikannya pengalaman yang baik atau buruk.

Berdasarkan premis diatas, maka hipotesis utama dalam penelitian ini adalah : " terdapat pengaruh yang signifikan antara servicescape yang terdiri dari ambient condition, spatial layout and functionality dan sign symbol and artifact terhadap behavioral intention".

\section{III.METODE PENELITIAN}

Objek dalam penelitian ini adalah tamu yang melakukan pembelian di Kafe Kupu-Kupu. Variabel bebas servicescape (X) yang terdiri dari ambient condition, spatial layout and functionality dan sign, symbol, and artifacts. Sedangkan untuk variabel terikat behavioral intention (Y) yang terdiri dari repurchase intention dan word of mouth. Populasi dalam penelitian ini adalah tamu yang melakukan pembelian di Kafe Kupu-Kupu pada Tahun 2014.

Teknik sampling yang digunakan dalam penelitian ini adalah Systematic Random Sampling, didapat sampel sejumlah 100 responden Penelitian ini menggunakan pendekatan cross sectional karena dilakukan dalam waktu kurang dari satu tahun. metode yang digunakan dalam penelitian ini adalah metode penelitian deskriptif dan verifikatif dimana dalam penelitian ini akan diuji pengaruh servicescape terhadap behavioral intention di Kafe Kupu-Kupu

Teknik pengumpulan data yang dilakukan penulis adalah dengan cara melakukan wawancara, observasi, kuisioner dan studi literatur. Untuk memperoleh hasil pengaruh servicescape terhadap behavioral intention penulis menggunakan teknik analisis data regresi berganda.

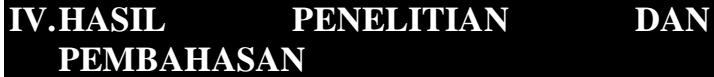

Berdasarkan hasil penelitian tamu mengenai tanggapan atribut servicescape di Kafe KupuKupu yang mendapatkan penilaiaan tertinggi sesuai dengan tanggapan konsumen adalah sign, symbol, and artifact yaitu sebesar $35 \%$ hal ini disebabkan para tamu Kafe Kupu-Kupu merasakan kesesuai antara brand kafe dengan sign, symbol, and artifact yang digunakan dalam interior maupun eksterior di Kafe Kupu-Kupu. Sedangkan atribut lain yang mendapatkan penilaian yang terendah adalah ambient condition sebesar $32,03 \%$ yang tidak terlalu berbeda jauh dengan spatial layout and functionality yaitu sebesar $32,95 \%$.

Sedangkan untuk atribut behavioral intention di Kafe Kupu-Kupu yang mendapatkan penilaiaan tertinggi sesuai dengan tanggapan konsumen adalah word of mouth yaitu sebesar $51.35 \%$, terlihat dari pengalaman responden tentang sumber informasi yang mereka dapat dari teman mengenai Kafe Kupu-Kupu merupakan hasil dari word of mouth pula. Sedangkan atribut lain yaitu repurchase intention memiliki penilaian sebesar $48.64 \%$ yang tidak terlalu berbeda jauh dengan word of mouth, niat tamu untuk membeli kembali produk dan jasa yang ditawarka Kafe Kupu-Kupu cukup baik.

Pengujian hipotesis secara simultan (Uji $\mathrm{F} /$ Tabel Anova) menunjukan bahwa nilai $\mathrm{F}_{\text {hitung }}=$ 21,573 dengan tingkat probabilitas sig. 0,000. Oleh karena nilai signifikansi 0,000 lebih kecil dari taraf signifikansi $5 \%(0,05)$ maka dapat dikatakan bahwa model fit dan dapat memprediksikan behavioral intention. Menurut perhitungan didapat Ftabel $=2,14$ atau $F_{\text {hitung }}>F_{\text {tabel }}$ yaitu 21,573 > 2,16. Maka $\mathrm{H}_{0}$ ditolak dan $\mathrm{Ha}$ diterima. Secara keseluruhan atau simultan variabel independen Servicescape (X) yang terdiri dari ambient condition, spatial layout and functionality dan sign, symbol, and artifacts berpengaruh secara signifikan terhadap variabel dependen yaitu behavioral intention (Y).

Sedangkan secara parsial melalui uji $t$ menunjukkan bahwa terdapat pengaruh dari atribut-atribut servicescape terhadap behavioral intention. Pengambilan kesimpulan berdasarkan pada pengujian yang dilakukan dengan cara membandingkan $t_{\text {hitung }}$ dengan $t_{\text {tabel }}$ yang nilainya sebesar 1,984. Dengan hasil ambient condition sebesar 2,098, spatial layout and functionality sebesar 2,389 dan sign, symbol, and artifacts sebesar 3,149. Melalui hasil analisis regresi berganda didapat persamaan sebagai berikut:

$$
\begin{aligned}
& Y=a+b_{1} X_{1}+b_{2} X_{2}+b_{3} X_{3} \\
& Y=4,049+0,067 X_{1}+0,113 X_{2}+0,518 X_{3}
\end{aligned}
$$


Nilai koefisien regresi 0,067 menyatakan apabila ambient condition $\left(\mathrm{X}_{1}\right)$ ditambahkan satu satuan, maka nilai behavioral intention tamu akan meningkat sebesar 0,067 , nilai koefisien regresi 0,113 menyatakan apabila spatial layout and functionality $\left(\mathrm{X}_{2}\right)$ ditambahkan satu satuan, maka behavioral intention tamu akan akan meningkat sebesar 0,113, nilai koefisien regresi 0,518 menyatakan apabila sign, symbol, and $\operatorname{artifact}\left(\mathrm{X}_{3}\right)$ ditambahkan satu satuan, maka behavioral intention tamu akan akan meningkat sebesar 0,518.

\section{KESIMPULAN \& REKOMENDASI}

Secara keseluruhan servicescape yang di laksanakan di Kafe Kupu-Kupu cukup baik. Hal ini sesuai dengan tanggapan dan penilaian tamu terhadap servicescape. Hasil penelitian menunjukan bahwa servicescape dapat mempengaruhi behavioral intention di Kafe KupuKupu. Namun dalam beberapa pelaksanaan masih terdapat kekurangan seperti rendahnya penilaian ambient condition. Oleh karena itu penulis menyarankan agar manjemen Kafe Kupu-Kupu dapat meningkatkan ambient condition contohnya menciptakan suasana yang lebih nyaman bagi tamu, mulai dari pencahayaan, warna cat, kebersihan dan suhu ruangan di Kafe Kupu-Kupu.

\section{DAFTAR PUSTAKA}

Baker, D.A dan Crompton, J.L. 2000. Quality, Satisfaction And Behavioral Intentions, Great Britanian: Annalis of Tourism Research
Fitzsimmons, James A and Mona J. Fitzsimmons. 2011. Service Management:

Operations, Strategy, Information Technology 7th edition,. The McGrawHill. International Edition.

Hsu, Maxwell K, Yinghua Huang, and Scott Swanson . 2009. Grocery Store Image, Travel Distance, Satisfaction and Behavioral Intentions, Taiwan : International Journal of Retail \& Distribution Management.

Kotler, Philip and Gary Amstrong. 2014. Priciples of Marketing Global 15th edition, New Jersey: Prentice.

Lovelock, Christopher dan Jochen Wirtz. 2011. Service Marketing:People, Technology, Strategy. 7th edition, New Jersey: Pearson Hall.

Oka A. Yoeti. 1990. Pengantar Ilmu Pariwisata, Bandung: Angkasa

R.G. Soekadijo. 2002. Anatomi Pariwisata : Memahami Pariwisata sebagai Sistemic Linkage, Jakarta : Gramedia Pustaka Utama.

Wahab, Crampon, Rothfield. 1997. Pemasaran Pariwisata, Jakarta: PT Pradnya Paramita

Wahyuningsih. 2011. Asean Marketing Journal, Palu: Tadulako University 